Practitioner Report

\section{Tailoring a Cognitive Behavioural Model for Unexplained Physical Symptoms to Patient's Perspective: A Bottom-Up Approach}

\author{
Lyonne N. L. Zonneveld, ${ }^{1,2 *}$ Hugo J. Duivenvoorden, ${ }^{2}$ \\ Jan Passchier ${ }^{2,3}$ and Adriaan van 't Spijker ${ }^{2}$ \\ ${ }^{1}$ Riagg Rijnmond, Vlaardingen, The Netherlands \\ ${ }^{2}$ Department of Medical Psychology and Psychotherapy, Erasmus MC, \\ Rotterdam, The Netherlands \\ ${ }^{3}$ Department of Clinical Psychology, VU University Amsterdam, Amsterdam, \\ The Netherlands
}

The prevalence of unexplained physical symptoms (UPS) in primary care is at least $33 \%$. Cognitive behavioural therapy has shown to be effective. Within cognitive behavioural therapy, three models can be distinguished: reattribution model, coping model and consequences model. The consequences model, labelling psychosocial stress in terms of consequences rather than as causes of UPS, has high acceptance among patients and is effective in academic medical care. This acceptance is lost when applied in primary care. To increase acceptance of the consequences model among patients in primary care, we tailor this model to patient's perspective by approaching the model from bottom-up instead of top-down. Subsequently, we use this tailored model in an easily accessible group training. We illustrate our approach using two illustrative cases. Copyright () 2010 John Wiley \& Sons, Ltd.

Key Practitioner Message:

- The prevalence of unexplained physical symptoms (UPS) in primary care is at least $33 \%$.

- Cognitive behavioural therapy has shown to be most effective for UPS. The most interesting cognitive behavioural model is the consequences model because $81 \%$ of the patients with UPS in secondary care accepts a therapy based on this model.

- The consequences model labels psychosocial stress as consequences rather than as causes of UPS and aims to change the consequences in that UPS reduces.

*Correspondence to: Lyonne Zonneveld, Riagg Rijnmond, Westhavenkade 85, 3133 AV Vlaardingen, The Netherlands. E-mail: lzonneveld@riaggrijnmond.nl; 1.zonneveld@erasmusmc.nl

The authors declare that they do not have conflicts of interest by publishing this report. 
- The acceptance of the consequences model drops in primary care, making a therapy based on this model not feasible for primary care.

- If the acceptance of the consequences model in primary care could be raised by tailoring this model more closely to patients' perspective of their symptoms approaching the model innovatively from bottom-up, then the opportunity of a positive outcome for patients in primary care could be improved.

Keywords: Behavioural Medicine, Group Therapy, Quality Of Life, Somatoform Disorders, Treatment Outcome, Unexplained Physical Symptoms

\section{Trial registration:}

Nederlands Trial Register, NTR1609

http:/ / www.trialregister.nl/trialreg/admin/rctview.asp?TC=1609

\section{INTRODUCTION}

In primary care, the prevalence of unexplained physical symptoms (UPS) is estimated to be about $33 \%$ (Kroenke, 2003). For UPS, cognitive behavioural therapy has shown to be most effective in secondary care, while evidence for its effectiveness in primary care is less distinct (Kroenke, 2007; Raine et al., 2002; Sumathipala, 2007). Within cognitive behavioural therapy for UPS, three models can be distinguished: the reattribution model, the coping model and the consequences model (Van der Mast, 2006). In the reattribution model, the line of reasoning is that the cause of UPS is psychosocial stress, depression or anxiety. The reattribution model aims to explain how symptoms can relate to psychosocial problems, depression or anxiety (reattribution) to improve UPS or to treat any underlying psychological or social problems. In the coping model and the consequences model, the line of reasoning is that the cause of UPS is unknown. The coping model aims to cope with the UPS to reduce stress, whereas the consequences model aims to change the consequences of UPS that maintain or even increase UPS to alleviate UPS.

The consequences model is most interesting because it combines the benefits of the other two models. It shows the interaction between body and mind, and also labels psychosocial stress as a consequence rather than a cause preventing the suggestion that 'its all in the head'. Moreover, $81 \%$ of the patients in an academic medical setting accepts a therapy based on this model (Speckens, Van Hemert, Bolk, Hawton, \& Rooijmans, 1995). A therapy based on this model (Figure 1: black arrows) starts with disputing the beliefs in reaction to UPS as irrational and replacing them with rational ones, followed by changing the con- sequences to break the vicious circle (Speckens, Spinhoven, Hawton, Bolk, \& Van Hemert, 1996; Speckens, Spinhoven, \& Van Rood, 1999). In an academic medical setting, this therapy is shown to be effective (Speckens et al., 1995). In primary care, the acceptance of a group therapy based on this approach drops, despite the use of the same procedure and methodology introduced to patients by the same person. This low acceptance makes this approach of the consequences model not feasible for primary care (Arnold, Speckens, \& Van Hemert, 2004), while the high prevalence of UPS asks for a high acceptable and easily accessible cognitive behavioural management of UPS.

We wish to tailor the consequences model more closely to patients' perspective in that it can lay the foundation of a highly acceptable and easily accessible cognitive behavioural group training for patients with UPS in primary care. We assume that patients in primary care have a physical perspective of their symptoms in that they formulate their complaints in terms of physical problems. Therefore, we approach the consequences model bottom-up (Figure 1: dotted arrows) starting with UPS and visible physical consequences instead of top-down (Figure 1: black arrows) starting with UPS and the psychological beliefs. In this bottomup approach, the visible consequences are labelled as survival strategies, of which existence is beneficial and justified in short term but harmful in the long run. Therefore, these strategies should be replaced by beneficial strategies in the long run. Subsequently, the underlying beliefs of these strategies are explored and, if necessary, adapted to reality to make them also beneficial in the long run. The newly acquired information about the differences in survival strategies and their own growing experiences with new strategies will make this 


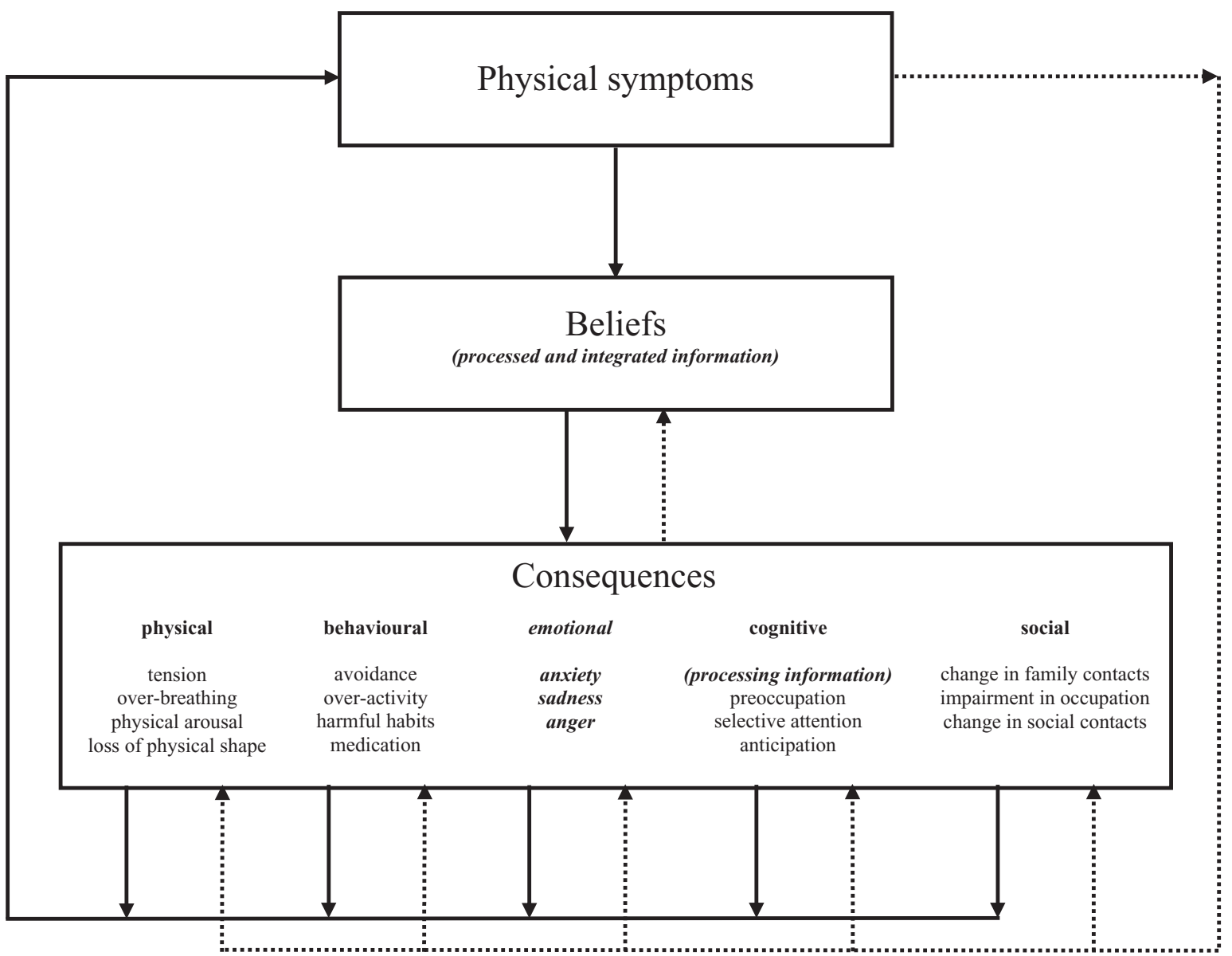

Top-down strategy:

Bottom-up strategy:

Figure 1. Tailored consequences model based on Speckens, Spinhoven, Hawton, Bolk, \& Van Hemert, 1996; Speckens, Spinhoven, \& Van Rood, 1999

adaptation easier. Finally, the problem-solving model of Nezu, Nezu, Friedman, Faddis and Houts (1998) is introduced to facilitate the development of personal effective survival strategies for all kind of problems, acknowledging that physical symptoms may increase the number of problems. The ultimate goal is to improve quality of life.

The bottom-up approach results in 13 weekly protocollized training sessions of 2 hours each, with the following structure:

1. sharing experiences of the past week;

2. discussing home-assignments;

3. doing a group breathing and relaxation exercise;
4. identifying short-term beneficial survival strategies and modifying them into long-term beneficial ones;

5. ending with a summary of the session and new home-assignments. (Zonneveld, 2005; Zonneveld, Van 't Spijker, Passchier, Van Busschbach, \& Duivenvoorden, 2009).

Table 1 shows the long-term beneficial survival strategies introduced in each session.

The training may be made easily accessible by implementing it on a location preferred by primary care physicians and patients. Furthermore, easy access to the training may also be reached by asking 
Table 1. The long-term beneficial survival strategies introduced in each session

\begin{tabular}{|c|c|}
\hline Session(s) & Long-term beneficial survival strategies \\
\hline 1 & $\begin{array}{l}\text { Getting acquainted with each other } \\
\text { Setting personal goals for the training }\end{array}$ \\
\hline 2 & $\begin{array}{l}\text { Practising the breathing and relaxation exercise } \\
\text { Substituting the habits with potential harmful effects in the long run with incompatible beneficial } \\
\text { habits }\end{array}$ \\
\hline 3 & $\begin{array}{l}\text { Scheduling different kind of activities in a feasible pace with short breaks preventing avoidance and } \\
\text { overactivity }\end{array}$ \\
\hline $4-5$ & Identifying emotions and thoughts and optimizing them with the Ellis' ABCDE scheme \\
\hline 6 & $\begin{array}{l}\text { Improving physical shape by doing a daily low cardiac physical activity } \\
\text { Expanding this physical activity with } 1 \text { minute every day }\end{array}$ \\
\hline 7 & Discussing consequences of physical symptoms with an important and true-hearted person \\
\hline $8-12$ & $\begin{array}{l}\text { Practising the five steps of the problem-solving method (problem-attitude, problem-definition, } \\
\text { alternative solutions, solution plan and solution implementation and evaluation) }\end{array}$ \\
\hline 13 & Assembling the long-term beneficial survival strategies in a personal First Aid Kit preventing relapse \\
\hline
\end{tabular}

primary care physicians only to confirm UPS and to refer to the training. This role may be welcome to most of the primary care physicians, because they view medical investigation as their core business and evaluate their psychological skills for patients with UPS as insufficient (Salmon, Peters, Clifford, Iredale, Gask, Rogers, Dowrick, Hughes, \& Morriss, 2007). Referral to the training may be acceptable for patients because of its tailoring to their perspective.

Below, this training based on the tailored consequences model is illustrated by presenting the experiences of two patients who participated in the group training: one of them, Anouk, with a beneficial outcome, and the other, Bernadette, with an unfavourable result.

\section{Case 'Anouk'}

'Anouk' is a 50-year-old married woman with an 11-year history of fibromyalgia. She receives full disability welfare. Nevertheless, she does a lot of voluntary work and she is a trainer in informal care.

Anouk grew up with a schizophrenic mother, to whom she could not express her emotions. She received inpatient mental treatment for an identity problem in 1993 and outpatient mental treatment for a depression in 1996.

After referral by her general practitioner, we invite Anouk to inform her about the training. Because of the holidays, she cancels twice, asking invariably for a new invitation. After the third invitation, she arrives in a mobility scooter wearing braces round her wrists. After the interview, Anouk finishes the Structured Clinical Interview for DSM-IV Axis I disorders (SCID-I) (First, Spitzer, Gibbon, \& Williams, 2001) and the self-report questionnaire for DSM-IV Axis II personality disorders (VKP) based on the International Personality Disorder Examination (Duijsens \& Eurelings-Bontekoe, 1999). The SCID-I shows a previous single episode depressive disorder and a pain disorder. The VKP indicates a paranoid and an obsessive-compulsive personality disorder.

Anouk's aim is 'contributing to the training and research as an expert and trainer in informal care'. She remarks spontaneously to the trainer: 'I am so glad that you called it a training instead of a group therapy!'

In the sessions, Anouk shares her experiences freely, although she reports difficulty with being a trainee instead of a trainer. She realizes that her use of orthopaedic devices and her busy day schedule have become harmful. She reduces her device use, builds in short breaks to recuperate and does not work on the computer after 20.00 hours anymore. Anouk misses the session on emotional consequences. She catches up on this subject when improving physical shape is introduced as a long-term beneficial survival strategy. Anouk expresses her anger towards the trainer. Anouk thinks that the trainer is wrong about the beneficial effect of improving one's physical shape. On physicians' advice in the past, Anouk has tried several times to improve her physical shape, leading to dramatic relapse and no support of these physicians. The trainer validates her anger and also 


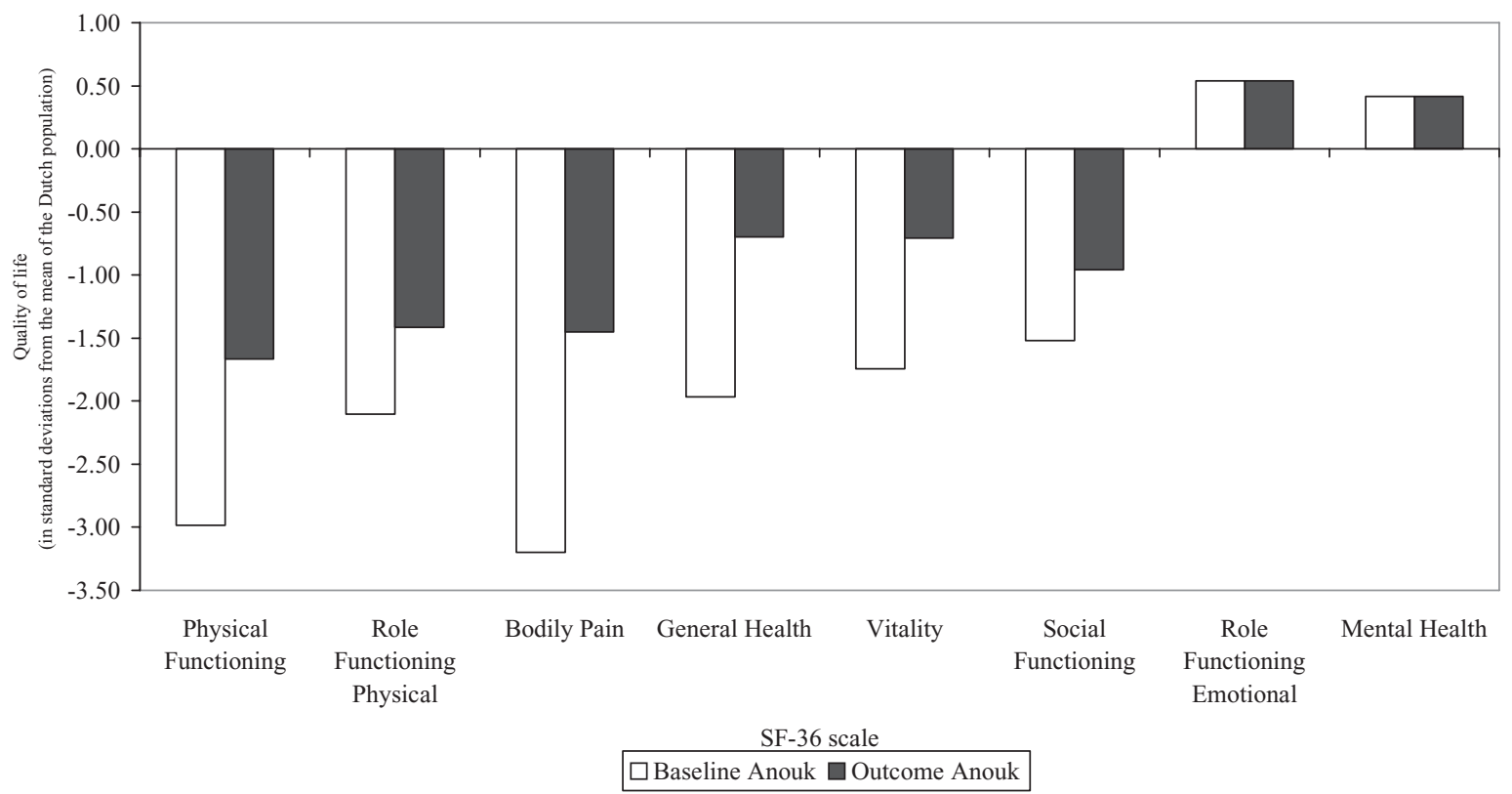

Figure 2. Anouk's quality of life before and after the group training in comparison with the general Dutch population

repeats the psycho education on the beneficial physiological mechanism underneath this strategy. In accordance with the training protocol, the trainer promises to weekly evaluate whether this survival strategy is also beneficial for Anouk's body. Anouk reports in the next session that she wants to improve her physical shape, albeit in a lower speed. Her courage is complimented. At the end of the training, Anouk does not use her braces or mobility scooter anymore. She enrols herself for Nordic Walking classes and reports less symptoms and less sleeplessness. Anouk's evaluation of the training is: 'My symptoms are definitely physical, but the cause of my symptoms is medically unexplained yet. This training recognizes patients are burdened and it is doing something for them. I did not want to miss the training for the world, even as an old stager. You always get something out of this training.'

To quantify the outcome on quality of life, Anouk fills in Short Form Health Survey (SF-36) before and after the group training. The SF-36 is a validated and reliable self-report questionnaire with 36 questions and standardized response choices for assessing quality of life. The quality of life is measured by eight multi-item scales: Physical Functioning, Role Functioning Physical, Bodily Pain, General Health, Vitality, Social Functioning, Role Func- tioning Emotional and Mental Health. A higher score indicates a better quality of life. Figure 2 shows Anouk's quality of life in standard deviations from the mean found in the general Dutch population.

\section{Case 'Bernadette'}

'Bernadette' is a 26-year-old married woman with a 10-year history of chronic fatigue. Her medical history shows glandular fever in 1998, after which her fatigue persists. In 1998, her mother left for another man, leaving Bernadette with her alcoholaddicted father. Bernadette works 32 hours weekly as a switchboard operator.

After referral by her general practitioner, Bernadette is informed about the training. After the interview, Bernadette finishes the SCID-I and VKP. The SCID-I shows an undifferentiated somatoform disorder. The VKP indicates no personality disorder. Bernadette's aim for the training is 'doing things despite my fatigue by spacing time appropriately'.

Bernadette hides herself in the background. She misses the problem-solving session about defining goals and making her own survival strategies towards them. At the end of the training, she starts sharing her daily life. Bernadette evaluates the 


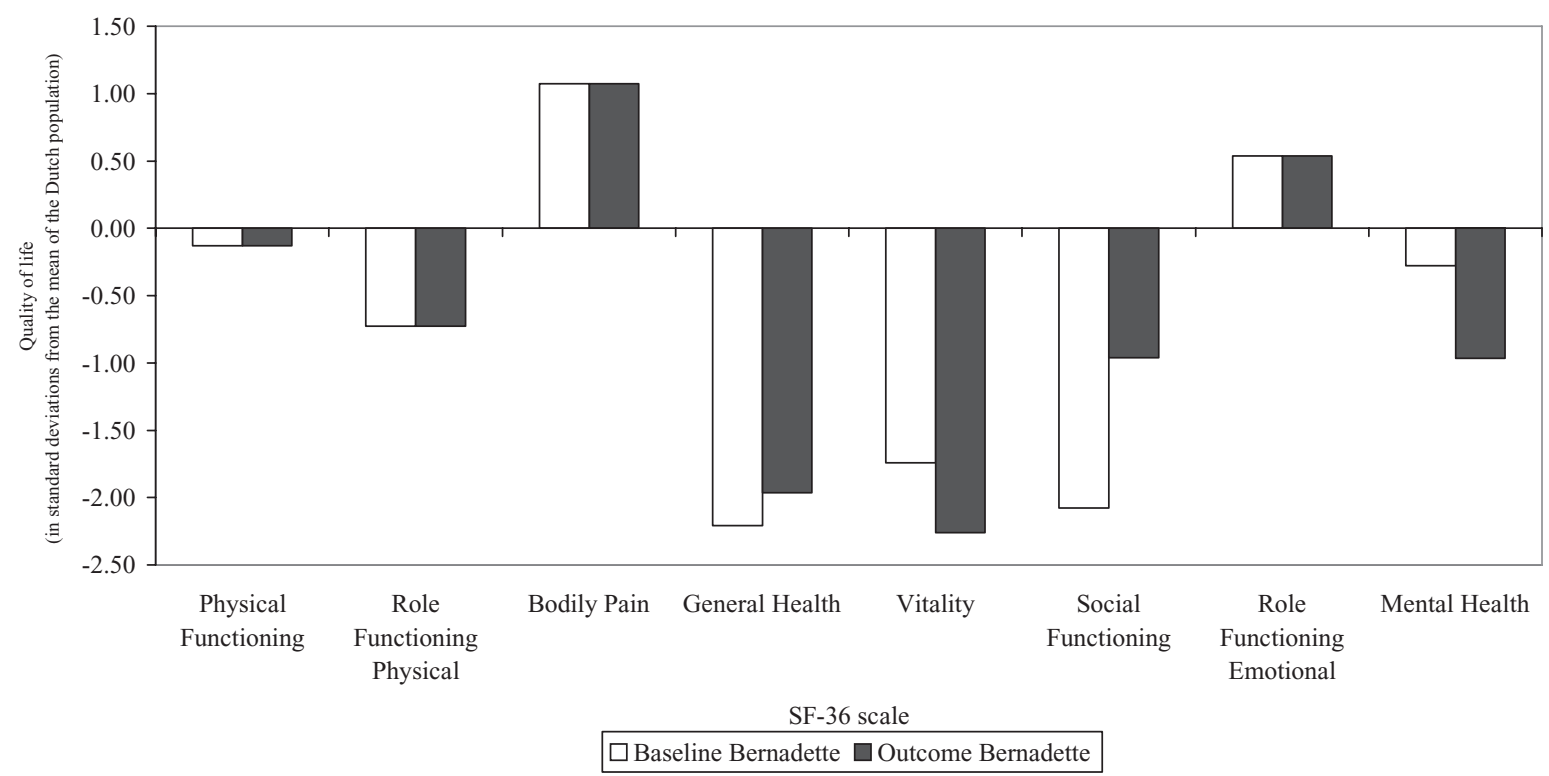

Figure 3. Bernadette's quality of life before and after the group training in comparison with the general Dutch population

training as informative but not applicable because of her 'busy day schedule'.

To quantify the outcome on quality of life, Bernadette fills in SF-36 before and after the group training. Figure 3 shows Bernadette's quality of life in standard deviations from the mean found in the general Dutch population.

After the ending of the sessions, Bernadette asks the trainer for 'an interview with a psychologist because of my anxiety anticipating the death of people around me. I am tired due to too much ruminating about awful things and I puzzled my head off'. We arrange psychotherapy, in which she engages.

\section{DISCUSSION}

We tailored the consequences model to our assumption that patients have a physical perspective of their symptoms by approaching the consequences model from bottom-up (starting with consequences and unconditionally accepting and justifying their existence) instead of top-down (starting with addressing irrational beliefs and disputing them). Our assumption that patients in primary care have a physical perspective seems to be supported by the two patients presented, who report their suffering on the SF-36 typically in physical terms. Also, Anouk's spontaneous remarks ('I am so glad that you called it a training instead of a group therapy!' and 'My symptoms are definitely physical, ...') show preference for physical terms.

Our assumption about patients' physical perspective can be tuned by recent research. Peters, Rogers, Salmon, Gask, Dowrick, Towey, Clifford, and Morriss (2008) find that patients use a multifaceted explanatory model, which includes both physical and psychosocial factors and the interaction between them. Sumathipala et al. (2008) show that the explanatory model viewed by nonWestern patients is more blank. In this study, $56 \%$ of the patients could not offer a specific cause for their UPS. Dwamena, Lyles, Frankel and Smith (2009) and Schweickhardt, Larisch and Fritzsche (2005) conclude that the explanatory model viewed by patients with UPS in primary care differs between significant understanding of psychological factors of their disease and much lesser psychological insight. They classify the majority of the patients as having less psychological insight. Even if patients have a multifaceted explanatory model, they would communicate only about the physical factors (Peters et al., 2008). Therefore, our assumption that patients in primary care formulate their complaints in terms of physical problems seems to hold. The best chance that 
patients accept the training is tailoring it to this physical perspective.

To take this initial acceptance to the next level, a match between patients' and trainings' goals must be established. As well as in patients using a multifaceted explanatory model (Peters et al., 2008) as in patients with less psychological insight (Dwamena et al., 2009), as in common patients with UPS (Nordin, Hartz, Noyes, Anderson, Rosenbaum, James, Ely, Agarwal, \& Levy, 2006), support is the most highly valued goal by patients. In the tailored consequences model, the bottom-up approach provides a high amount of support. By justifying patients' reactions to their UPS because of its benefits in short term, patients are relieved from blame, supported in their reactions to cope and trusted that they can use even more sophisticated reactions to improve their quality of life. Because support and relief from being blamed are also common factors that facilitate the development of a working alliance, the likelihood of beneficial effects of the bottom-up approach is increased (Lambert, 2005). All in all, this approach seems promising for the working alliance.

Anouk seems to bond easily with the trainer, allowing even a self-disclosure about her difficulties of being a trainee. However, expressing her anger towards her trainer must have been difficult, because in her childhood, expression of emotions was not tolerated. But, as her anger is unconditionally accepted, the opportunity comes up to negotiate further about goals and tasks. In other words, a working alliance can be more firmly established. As Anouk has a paranoid and obsessivecompulsive personality disorder, this is even more striking.

Bernadette has difficulties with being prominent, let alone to bond with her trainer. This is not surprising, as at the age of 16 her mother left her, just when she was individuating. Hereby, individuating might be associated with abandonment by others. Her increased participation in the group may reflect an increased faith in being accepted. Her reported anxiety concerning the possible death of loved ones, suggests that she still questions the unconditionality of acceptance. Although the working alliance is still premature for stable beneficial change, it is sufficient to start psychotherapy.

Our group training seems to match the-by patients most frequently communicated-perspective of UPS and patients' goal for management of their UPS. This facilitates working alliances, even when the childhood experiences with bonding are unfavourable. Working alliances robustly predict beneficial therapy outcome (Lambert, 2005). A randomized controlled trial is ongoing to explore if the group training is indeed as promising as it seems to be.

\section{ACKNOWLEDGEMENTS}

The first author is indebted to the trainees and Riagg Rijnmond, The Netherlands. This group training could not have been developed and conducted without the trainees, colleagues, financial support and facilities of Riagg Rijnmond Rotterdam/Vlaardingen.

\section{REFERENCES}

Arnold, I.A., Speckens, A.E.M., \& Van Hemert, A.M. (2004). Medically unexplained physical symptoms: The feasibility of group cognitive-behavioural therapy in primary care. Journal of Psychosomatic Research, 57(6), 517-520.

Duijsens, I.J., \& Eurelings-Bontekoe, E.H.M. (1999). Handleiding van Vragenlijst Kenmerken van Persoonlijkheid. Leiderdorp: Datec.

Dwamena, F.C., Lyles, J.S., Frankel, R.M., \& Smith, R.C. (2009). In their own words: Qualitative study of high-utilising primary care patients with medically unexplained symptoms. BMC Family Practice, 10(67), doi:10.1186/1471-2296-10-67.

First, M.B., Spitzer, R.L., Gibbon, M., \& Williams, J.B.W. (2001). Structured clinical interview for DSM-IV Axis I disorders (M.A.C. Van Groenesteijn, G.W. Akkerhuis, R.W. Kupka, N. Schneider, \& W. A. Nolen, Trans.). Lisse: Swets Test Publishers.

Kroenke, K. (2003). Patients presenting with somatic complaints: Epidemiology, psychiatric co-morbidity and management. International Journal of Methods in Psychiatric Research, 12(1), 34-43.

Kroenke, K. (2007). Efficacy of treatment for somatoform disorders: A review of randomized controlled trials. Psychosomatic Medicine, 69(9), 881-888.

Lambert, M.J. (2005). Early response in psychotherapy: Further evidence for the importance of common factors rather than 'placebo effects'. Journal of Clinical Psychology, 61(7), 855-869.

Nezu, A.M., Nezu, C.M., Friedman, S.H., Faddis, S., \& Houts, P.S. (1998). Helping cancer patients cope: A problem-solving approach. Washington, DC: American Psychological Association.

Nordin, T.A., Hartz, A.J., Noyes, R., Anderson, M.C., Rosenbaum, M.E., James, P.A., et al. (2006). Empirically identified goals for the management of unexplained symptoms. Family Medicine, 38(7), 476-482.

Peters, S., Rogers, A., Salmon, P., Gask, L., Dowrick, C., Towey, M., et al. (2008). What do patients choose to tell their doctors? Qualitative analysis of potential barriers to reattributing medically unexplained symptoms. Journal of General Internal Medicine, 24(4), 443-449. 
Raine, R., Haines, A., Sensky, T., Hutchings, A., Larkin, K., \& Black, N. (2002). Systematic review of mental health interventions for patients with common somatic symptoms: Can research evidence from secondary care be extrapolated to primary care? BMJ, 325, 1082-1092.

Salmon, P., Peters, S., Clifford, R., Iredale, W., Gask, L., Rogers, A., et al. (2007). Why do General Practitioners decline training to improve management of medically unexplained symptoms? Journal of General Internal Medicine, 22(5), 565-571.

Schweickhardt, A., Larisch, A., \& Fritzsche, K. (2005). Differentiation of somatizing patients in primary care: Why the effects of treatment are always moderate. Journal of Nervous and Mental Disease, 193(12), 813-819.

Speckens, A.E.M., Spinhoven, P., Hawton, K.E., Bolk, J.H., \& Van Hemert, A.M. (1996). Cognitive behavioural therapy for medically unexplained physical symptoms: A pilot study. Behavioural and Cognitive Psychotherapy, 24(1), 1-16.

Speckens, A.E.M., Spinhoven, P., \& Van Rood, Y. R. (1999). Protocollaire behandeling van patiënten met onverklaarde lichamelijke klachten: Cognitieve gedragstherapie. In G.P.J. Keijsers, A. Van Minnen, \& C.A.L. Hoogduin (Eds), Protocollaire behandelingen in de ambulante geestelijke gezondheidszorg 2 (pp. 199-236). Houten/Diegem: Bohn Stafleu Van Loghum.

Speckens, A.E.M., Van Hemert, A.M., Bolk, J.H., Hawton, K.E., \& Rooijmans, H.G.M. (1995). The acceptability of psychological treatment in patients with medically unexplained physical symptoms. Journal of Psychosomatic Research, 7, 855-863.
Speckens, A.E.M., Van Hemert, A.M., Spinhoven, P., Hawton, K.E., Bolk, J.H., \& Rooijmans, H.G.M. (1995). Cognitive behavioural therapy for medically unexplained physical symptoms: A randomised controlled trial. British Medical Journal, 311, 1328-1332.

Sumathipala, A. (2007). What is the evidence for the efficacy of treatments for somatoform disorders? A critical review of previous intervention studies. Psychosomatic Medicine, 69(9), 889-900.

Sumathipala, A., Siribaddana, S., Hewege, S., Sumathipala, K., Prince, M., \& Mann, A. (2008). Understanding the explanatory model of the patient on their medically unexplained symptoms and its implication on treatment development research: A Sri Lanka Study. BMC Psychiatry, 8, 54 .

Van der Mast, R.C. (2006). Onverklaarde lichamelijke klachten: een omvangrijk probleem, maar nog weinig zichtbaar in opleiding en richtlijnen. Nederlands Tijdschrift voor Geneeskunde, 150(12), 686-692.

Zonneveld, L.N.L. (2005). Draaiboek 'Omgaan met de gevolgen van medisch onverklaarde lichamelijke klachten'. Unpublished Ad verbatim manual. Riagg Rijnmond/Erasmus Medical Center, Department of Medical Psychology and Psychotherapy.

Zonneveld, L.N.L., Van 't Spijker, A., Passchier, J., Van Busschbach, J.J., \& Duivenvoorden, H.J. (2009). The effectiveness of a training for patients with unexplained physical symptoms: Protocol of a cognitive behavioral group training and randomized controlled trial. BMC Public Health, 9(251), doi:10.1186/1471-2458-9-251. 
Copyright of Clinical Psychology \& Psychotherapy is the property of John Wiley \& Sons, Inc. and its content may not be copied or emailed to multiple sites or posted to a listserv without the copyright holder's express written permission. However, users may print, download, or email articles for individual use. 